\title{
La introducción en Francia de los métodos de sondeo aleatorio ${ }^{1}$
}

\author{
Michael ARMatTe \\ Université Paris-Dauphine \\ UFR Économie appliquée \\ michel.armatte@dauphine.fr
}

\section{INTRODUCCIÓN}

El texto que sigue ${ }^{2}$ está elaborado a partir de diferentes fuentes de información sobre la las primeras investigaciones por sondeo realizadas en Francia por instituciones como el INSEE, el INED y el IFOP, así como algunas otras más efímeras aparecidas entre el año 1938, cuando Stoetzel crea el IFOP, y 1954, año en la que Pierre Thionet abandona el servicio de sondeos del INSEE. La reciente desaparición de Pierre Thionet en abril de 2002 nos ha incitado a escribir este texto y a rendir un homenaje muy particular a sus trabajos sobre los sondeos y a una obra muy mal conocida. Este texto se apoya en diversas publicaciones y documentos de archivos, pero también sobre entrevistas realizadas a los principales actores de este período como Pierre Thionet (1996), su predecesor Henri Bunle, su colega del INSEE, Raymond Lévy-Bruhl, o su sucesor en el servicio de sondeos Jacques Desabie ${ }^{3}$.

${ }^{1}$ Traducción de Alejandro ALMAZAN y José M. ARRIBAS. Reedición con la autorización del Journal de la Société Française de Statistique. Ref.: ARMATTE, M. Pierre Thionet et l'introduction en France des méthodes de sondage aléatoire. Journal de la Société Française de Statistique, vol 144, $\mathrm{n}^{\circ} 1-2$, pp 227-255., Paris, 2003.

${ }_{2}$ Una primera versión de este texto fue redactada y presentada en el Seminario de Investigación del INSEE del 9 de mayo de 1996, posteriormente ha sido difundida de manera interna con ocasión de la celebración del cincuentenario del INSEE. Esta primera versión contribuía a una reflexión sobre la evolución de las encuestas sobre condiciones de vida en el INSEE desde finales del siglo XIX hasta nuestros días publicada de forma interna bajo el título: L' évolution des enquêtes «conditions de vie» de l'INSEE du XIX ${ }^{\text {eme }}$ siècle à nous jours y conteniendo también las aportaciones de Françoise Dussert, Alain Desrosières, Michel Glaude, y François Héran.

${ }^{3}$ Las entrevistas utilizadas son las siguientes: Henri Bunle por Alain Desrosiéres, Raymond Lèvy-Bruhl, por Alain Desrosiéres y Michel Armatte, Pierre Thionet por Jean-Claude Deville y Michel Ramat, Jacques Desabie por Alain Desrosiéres, Michel Glaude, François Héran, Françoise Dussert y Michel Armatte. 
Al situar el punto de partida de nuestro estudio en la Francia ocupada durante la Segunda Guerra Mundial, es evidente que no tomamos la historia de los sondeos desde el origen, ni en su dimensión internacional, pues esta primera parte de la historia ya ha sido objeto de numerosos trabajos, por ejemplo: Seng (1951), Kruskal y Mosteller (1980), O'Muircheartaigh y Wong (1981), Desrosiéres (1988), Armatte (1988), Tassi (1988), Desrosiéres (1993 y 2000), Fiemberg y Tanur (1996). No obstante, comenzaremos recordando cuales han sido las principales etapas de este proceso.

\section{LAS INVESTIGACIONES REPRESENTATIVAS ANTES DE 1936}

Los trabajos de Laplace sobre la teoría de errores, y su aplicación a la estimación de la población por el cociente población/nacimientos acompañado de un intervalo de confianza, ofrecen ya los primeros fundamentos probabilísticos de un juicio sobre la muestra, a finales del siglo XVIII. Pero la intensa actividad de producción de cifras en las oficinas estadísticas desde finales de los años 1820, lleva a las Administraciones y a la Estadística General de Francia, a privilegiar las investigaciones exhaustivas que parecen proporcionar el encuadramiento contable principal de las actividades sociales y económicas, mientras que las monografías de familia o de taller, así como las practicadas por Le Play, Villermé y Cheysson después de 1850 (sustentadas en el establecimiento de presupuestos detallados), ofrecen una información complementaria de riqueza incomparable aunque resultan imposibles de agregar. La investigación estadística exhaustiva constituiría, en cierto modo, el «esqueleto» de los fenómenos sociales, mientras que la monografía proporciona la «carne». Así sería la metodología dual propuesta por Cheysson a finales de los años 1880 .

La práctica de los sondeos representativos parece haberse desarrollado fundamentalmente en el contexto de las investigaciones agrícolas combinando estas dos tradiciones de la monografía y la investigación exhaustiva. Emmanuel Didier (2000) ha mostrado cómo el Departamento de Agricultura de los Estados Unidos empleaba desde 1863 «crop reporters», granjeros o no, voluntarios o elegidos, que «representan» a la comunidad de los granjeros de una circunscripción e informan a la Administración sobre las prácticas y las cosechas. A partir de 1921 los encuestados son todos granjeros y no representan más que su propia granja, se pasa, por tanto, de la opinión de un testigo a la declaración individual de un actor elegido como representante ${ }^{4}$. Después de 1924 se recurre a los carteros para distribuir los cuestionarios y ya no es un encuestado el que representa a una comunidad, sino todos los granjeros grandes y pequeños, de una porción de la ruta constituida como muestra, y cuya media será representativa. En Nor-

\footnotetext{
${ }^{4}$ E. Didier recuerda que el primer sentido de «sample» en el Departamento de Agricultura fue
} el de un caso ejemplar individual antes de ser una muestra de varias personas. 
uega (Lie, 2001), las encuestas agrarias realizadas a mitad de los años 1870 por Kiaer y Mohn en el marco del Central Bureau of Statistics, se realizan en 5 granjas representativas de su township y son complementadas por estudios en profundidad de los registros de la población de 56 townships, considerados cada uno de ellos como representativos de todo un distrito. En Rusia, como ha mostrado Martine Mespoulet (2000), Kaufman y Chuprov practican desde los años 1880 una forma de extracciones sistemáticas a veces combinadas con la selección de áreas-típicas, mientras que en $1900 \mathrm{Gurev}$ pone en práctica el método de la selección razonada en la encuesta de Vjatka, con un éxito confirmado por la concordancia con el censo de 1880 . En estos distintos ejemplos, los estadísticos, a la hora de construir su muestra, todavía todavía parecen dudar entre la representatividad del individuo medio típico, en el sentido de Quetelet y Le Play, y el de una muestra dotada de una variabilidad similar a la de la población, por el simple efecto de una extracción realizada al azar, o de fofma sistemática.

En el cambio de siglo, las encuesta parciales sobre la pobreza y luego sobre salarios, las condiciones de vida de los trabajadores, los presupuestos y el consumo, o incluso los seguros, van a constituir el sustrato de la reflexión sobre la representatividad de los resultados obtenidos a partir de sub-poblaciones que no aparecen aún como muestras. Las encuestas de Booth y Rowntree son muy artesanales y de escala modesta, pero la encuesta noruega de Strom realizada en 1888 sobre el consumo de azucar, café y petróleo, utiliza una muestra aleatoria de 18.000 hogares. La encuesta de Kiaer sobre las rentas y los activos de los años 1890 utiliza una muestra de 11.500 personas, que combina todavía una selección razonada de ciudades y de comunidades, con la extracción sistemática de personas en esas ciudades (según la primera letra de su nombre). La encuesta del Board of Trade inglesa (1909) sobre los costes comparados de la mano de obra (lanzada a escala europea desde 1905), las encuestas de Bowley en Reading (1913), o las encuesta alemanas utilizadas por Halbwachs en su tesis de 1913, se realizan sobre grandes muestras pero se limitan a los obreros de las grandes ciudades, habiéndose elegido los individuos de la muestra a través de organizaciones sindicales o cooperativas. La encuesta del SGF de 1913-14, dirigida por Dugé de Bernonville, ampliaba su campo a las familias de obreros, empleados, artesanos y asalariados agrícolas, pero la muestra (12.500 cuestionarios distribuidos, 3.700 recuperados y 2.000 explotados) no es aleatoria, aunque se había recomendado una extracción sistemática de las listas nominativas del censo de 1911 , la orden no se llevó a cabo y la elección de las familias encuestadas fue dejada al buen sentido de alcaldes, enseñantes, médicos e industriales, cuyas relaciones privilegiadas con los encuestados no podía garantizar la objetividad y la homogeneidad de la operación.

El debate sobre la legitimidad de las encuesta parciales es llevado por Kiaer (1895) ante las instancias del IIS (Instituto Internacional de Estadística) encargadas de discutir sobre el método representativo. Allí se recogen las críticas conjuntas de dos grupos: hay quien, como von Mayr, rechaza a priori el principio de sustitución de una una encuesta exhaustiva por una muestra y rechaza tam- 
bién toda aproximación matemática a la cuestión, y los que, como Bortkiewicz o Hjorth, aceptan el principio de la encuesta parcial, pero prueban mediante el cálculo de probabilidades que el método utilizado no es representativo, las desviaciones de la estimación respecto al valor verdadero no podían ser atribuidas al azar sino a un sesgo sistemático. La segunda de las encuestas de Kiaer se organiza para implantar un sistema de seguros, y la controversia técnica se inscribirá entonces en los juegos políticos y la rivalidad profesional entre actuarios y estadísticos (Lie, 2000). Kiaer muere seis años más tarde cuando retomado el debate en el IIS, se llega a la resolución de 1925 en la que se reconoce la validez de los sondeos bajo las dos formas, «purposive selection» y sondeo aleatorio (informe Jensen y Bowley, 1926).

La controversia sobre la posibilidad misma de tomar la parte por el todo (Desrosières, 1988) da lugar a una segunda controversia entre métodos representativos y métodos aleatorios. Los primeros, de tipo cuotas, proponen simplemente adoptar criterios «razonados» para limitar ciertos sesgos sistemáticos y asegurar a posteriori la representatividad. Por el contrario, las aproximaciones aleatorias se basan en los trabajos probabilistas de Gauss y Laplace, que hacia 1900 eran bastante desconocidos por investigadores sociales, sociólogos, economistas, e incluso los propios estadísticos.

La historia de los sondeos recorre un camino paralelo a las prácticas administrativas y los logros en estadística matemática. Es Athur Bowley el primero en haber presentado en las ediciones sucesivas de su tratado (Bowley, 1901) y en su Presidencial Adress (Bowley, 1906) los conocimientos mínimos de la teoría de los sondeos simples: ley de la fluctuación del muestreo, medida de la precisión e intervalos de variación. Entre 1920 y 1025 , la teoría de los sondeos se ve considerablemente enriquecida por las aportaciones de Ronald Fisher sobre la teoría de la estimación, que introducen la distinción entre parámetros de la población y estadísticos de la muestra, las propiedades de estos últimos cuando son tomados como estimadores, su formalización exacta para muestras pequeñas, el método de máxima verosimilitud y su vinculación a la eficacia de los estimadores (Armatte, 1988). En el mismo período, el análisis de la varianza y la introducción de la aleatoriedad en la práctica son introducidos y vulgarizados a gran escala por la publicación Statistical Methods for Research Workers (1925). La exposición de Bowley (1926) redactada con ocasión de la resolución de Jensen en el IIS, muestra los progresos habidos en los 20 años que separan este texto de su Presidencial Adress.

La etapa siguiente comienza con la primera visita de Jerzy Neyman a Londres en 1925 y el reconocimiento simultáneo de sus escritos polacos (bajo la influencia de Bernstein y Harkov) y los de Chuprov. El método de la selección razonada, puesto en práctica por Gini y Galvani - y presentada en el IIS (Gini, 1928)- para seleccionar 29 distritos entre 214 utilizando el censo italiano de 1921, es discutido paso a paso y descalificado por Neyman (1934) quien, en ese mismo artículo, introduce los intervalos de confianza y enuncia los principios de la estratificación óptima (Fienberg y Tanur, 1996). Sobre esta cuestión, Neyman reconocerá que sus resultados habían sido anticipados por la escuela rusa, y en particular por Chuprov 
y Kovalevskij, una docena de años antes (Mespoulet, 2000). Sobre la cuestión de los intervalos de confianza, la disputa con Fisher que defiende su método de los intervalos fiduciarios, será más viva en tanto entre en consonancia con otras controversias sobre los cuadrados latinos y sobre los test estadísticos, en un contexto sensibilizado por la crisis de sucesión de Kart Pearson en el University Colleage. Con la publicación de The Design of Experiments (1935), Fisher inscribe esta cuestión en el marco más general de la lógica inductiva experimental. La separación resulta inevitable entre problemáticas vinculadas al plano de la experiencia, que Fisher pone a punto en Rothamsted, y las relativas a las decisiones sobre la muestra, como el control de fabricación, y aún aquellas que acompañan el tratamiento de encuestas por sondeo en las administraciones. Y ello a pesar de las similitudes y los múltiples intercambios que se producen entre las matemáticas desarrolladas para estos tres tipos de problemas. El episodio francés que nos proponemos relatar sucede a estos avances y controversias de los años 30 y posee múltiples facetas, aunque se refiera esencialmente a la tradición de las encuestas.

\section{OPINIÓN, MUESTRA Y SONDEO EN 1936-45}

Volviendo a Francia, las encuestas más confidenciales de entre guerras - Antonelli en 1921 sobre el coste de la vida en Lyon, Delpech en 1937 sobre 100 hogares de Toulouse, Rist en Paris, Lyon, y Mulhouse en 1936-37 acerca de las familias de parados, quedan, por su tamaño y sus objetivos, más cerca de la monografía que de la encuesta estadística y parecen ignorar los avances téricos sobre los sondeos aleatorios. Como ha mostrado Blondiaux (1998), la técnica de los sondeos (llamados primero straw polls) no nace en el universo de la academia, sino en el del marketing y el periodismo. El célebre golpe de Gallup en las elecciones presidenciales americanas de 1936, traslada la cuestión de los sondeos del estado de la polémica al de la experimentación y de la predicción a la verdadera magnitud, es decir al estatus de método científico a los ojos de la mayoría. Previendo con la ayuda de una muestra por selección juiciosa de algunos miles de personas ${ }^{5}$ la victoria de Roosevelt, mientras que los «votos de paja» de varios millones de lectores de grandes diarios como el Literary Digest daban por vencedor a su adversario Landon, Gallup tuvo el conocimiento científico (;y la suerte?) para hacer una predicción ajustada a bajo coste, lo que contribuirá de forma importante en la legitimidad de los sondeos ${ }^{6} \mathrm{y}$, desgraciadamente, a la asimilación entre sondeo y opinión, entre sampling y pooling, confundiendo por mucho tiempo la innovación

\footnotetext{
${ }^{5} 1.500$ según ciertas leyendas, cerca de 100.000 , al menos, según Blondiaux.

"Esta "experiencia decisiva" fue tanto más convincente en cuanto las diferencias de previsión del Literary Digest y del Instituto Gallup eran enormes: $42,5 \%$ frente a $54 \%$ para Roosevelt, aunque debe ser relativizada por el hecho de que otros institutos de sondeos confirman la predicción de Gallup (como Roper con 3.000 entrevistas solamente) y que Roosvelt obtiene de hecho el $61 \%$ de los sufragios.
} 
debida al método (el juicio sobre la muestra representativa) con lo que revelaba del objeto (la opinión), y de su posible o imposible medición.

Pero el método de sondeos también se ha beneficiado de esta confusión, ya que se importa a Francia bajo el pretexto de los estudios de opinión. El primero que introduce los sondeos en Francia es sin duda Jean Stoetzel, un agregado de filosofía que funda el Instituto Francés de Opinión Pública en 1938, a la vuelta de un viaje por los Estados Unidos. El IFOP toma sus métodos de los institutos privados americanos como Gallup, e inicia la publicación de sus resultados con la investigación sobre el descenso de la natalidad, bajo la pluma de Henri Paoletti, en los tres primeros números de su revista Sondages, en 1939. Pero la guerra interrumpe las actividades del IFOP que no serán retomadas hasta la liberación. Jean Stoetzel trastada entonces sus actividades a la Fondation Française pour l'Étude des Problèmes Humains, una institución de investigación eugenista fundada en noviembre de 1941 por Alexis Carrel con ayuda de la Fundación Rockefeller, y vinculada al Secretariado de Estado para la Familia (Drouard, 1983 y Girard, 1986). Dirigida por François Perroux y después por J.J. Gillon, esta fundación contaba con 150-160 personas en vísperas de la suspensión de Carrel, en agosto de 1944. Desde febrero de 1942, la Fundación se dota de un - servicio de sondeos y estadística, que dirige Stoetzel con la ayuda de Alain Girard, ex profesor de letras en el liceo de Evreux y bibliotecario de la Biblioteca Nacional. Stoetzel y Girard movilizan datos sanitarios o escolares, y dirigen las investigaciones de la Fundación sobre cuestiones demográficas y sanitarias como la investigación sobre la natalidad de las mujeres jóvenes, la gran encuesta de 1944 sobre 100.000 niños, que será explotada más tarde por el INED, etc.

La Fundación Carrel no es la única que realiza sondeos bajo la ocupación. En los años 1941-44, la actividad del IFOP en materia de opinión pública fue relevada por otros organismos privados que se proclaman como él influenciados por Gallup. Un enigmático Service des Sondages et de Statistique (SSS) fundado en 1944 por Max Barioux en la clandestinidad, que se dice surgido de la Resistencia, envía sus encuestas de opinión a Argel y Londres. La CEGOS, fundada por el politécnico Milhaud, se dota igualmente, en 1943, bajo el impulso de su director M. Pouderoux, de una oficina de estadísticas y de sondeos que desarrolla conjuntamente estudios de mercado y sondeos de opinión. El asesor Jacques Dourdin montó su propia sociedad en 1938, para desarrollar la primera invención de Gallup, a saber, los estudios de mercado que vende a los industriales.

Como ha señalado Loïc Blondiaux, el período de Vichy no es especialmente favorable al desarrollo de los sondeos de opinión fuertemente asociados a los principios democráticos y a las libertades individuales, tras la retórica de Gallup. El régimen de Vichy prefiere hacerse una idea de la opinión pública de manera secreta, mediante un dispositivo de escuchas a gran escala? ${ }^{7}$. Pocos estableci-

${ }^{7}$ El servicio de «controles técnicos» vinculado directamente a Laval habría interceptado 2,5 millones de cartas, 1,8 millones de telegramas y 21.000 conversacones telefónicas, sólo en el mes de diciembre de 1943 (Blondiaux, 1998, p. 396) 
mientos públicos se interesan por los sondeos en este período, a excepción de una institución como el Instituto Nacional de Higiene, creado por una ley de $\mathbf{3 0}$ de noviembre de 1941, que procede regularmente a hacer encuestas alimentarias y sanitarias al margen de sus trabajos de laboratorio.

Del lado de la estadística oficial, la introducción de las primeras investigaciones mediante sondeos se sitúa en la dinámica de la constitución del SNS (Service Nacional des Statistiques). El controlador general de los ejércitos René Carmille que se había distinguido tanto por sus acciones de guerra en 1918 como por sus reformas contables y por sus conferencias en la facultad de Ciencias Políticas, es llamado en agosto de 1940 por el ministro de la guerra para reconstruir nuestro ejercito con ayuda de un sistema «completo y coherente» de información demográfica y económica, cuyos elementos clave son la información continuada, la identificación de personas, el mantenimiento de ficheros mecanografiados y la coordinación de todas las estadísticas (Touchelay, 1993). Carmille crea primero un servicio de Demografía en 1940, que fusiona oficialmente en 1941 con la SGF (Statistique Générale de la France) en un nuevo Service National des Statistiques. Éste se instala en Lyon pero enseguida se adjuntan numerosos centros regionales bien dotados de personas y máquinas. La vinculación administrativa de la pequeña y vieja SGF al SNS no es inmediata en la práctica: si Michel Huber antiguo director de la SGF y director del ISUP (Institut de Statistique de la Université de Paris), es tomado como consejero por Carmille desde el principio, luego es ayudado en septiembre de 1941 por Alfred Sauvy, cuyo Institut de Conjoncture, creado en 1938 en el Ministerio de Economía Nacional es vinculado también al SNS - parece que el nuevo director Henri Bunle reniega un poco de este matrimonio forzado (entrevista).

Es en este clima de cambios incesantes y de la dualidad entre administradores civiles y militares, entre zona ocupada y zona liberada, las técnicas de sondeo, a priori concurrentes con el sistema de ficheros de Carmille, van a ser tímidamente evaluados. Desde 1941 encontramos sus huellas en los estudios de biometría humana impulsados por Pierre Lombardy y llevados a cabo por los médicos militares que dirigen talleres regionales (Touchelay, 1993). También en la nota de 26 de junio de 1941, enviada por Paoletti (delegado de equipamiento) a Dulac, administrador del servicio Demográfico, en la que discute sobre los méritos de los sondeos del IFOP, de sus usos privados (por los profesionales de la publicidad ${ }^{8}$ ) y también, públicos. Esta cuestión de los sondeos debió suponer un problema para Carmille, pues solicita una comisión de expertos compuesta por Stoetzel, el administrador Sassi, y los profesores François Divisia, Paul Lévy y Jacques Chapelon. Mientras Stoetzel desarrolla los puntos técnicos y sentencia que no hay diferencia esencial entre el sondeo en una población y cualquier investigación experimental, Divisia contesta las hipótesis de normalidad de las

${ }^{8}$ La muerte de M. Bleustein-Blanchet en 1996 ha sido la ocasión de recordar en la prensa el papel que ha jugado en la introducción de los sondeos en Francia. 
distribuciones y la independencia de las extracciones que están en la base de los cálculos, y que en materia de opiniones no son verificados en un grupo social $a$ fortiori, ya que por esta causa, todos los métodos estadísticos generales pueden ser de una aplicación tanto más peligrosa en cuanto se presenten formalmente como más perfeccionados. Paul Lévy retoma la primera objeción de Divisia y concluye que cada aplicación práctica del teorema de De Moivre refiere al buen sentido y no a una regla que pueda aplicarse automáticamente. Chapelon insiste sobre la segunda objeción de Divisia, a saber, que en materia de variables subjetivas, las respuestas pueden ser sistemáticamente orientadas por toda suerte de influencias psicológicas, especialmente, puntualiza, en las circunstancias actuales. Él extiende finalmente esta inquietud mediante una cuestión bastante iconoclasta: ¿se puede estar seguro de que el porcentaje a medir "p» existe?, porque

el hecho de que existan las opiniones se debe a la ignorancia, pero si la ignorancia es demasiado grande, la noción de opinión desaparece. Las circunstancias actuales han creado esta ignorancia y han producido una especie de licuefacción de la opinión. La gente piensa de modo diferente dependiendo del interlocutor o de la hora del dí. No tienen ya una opinión, sino que oscilan entre el escepticismo y la credulidad. En tiempos normales, cuando la opinión se ha cristalizado, es ya suficientemente elusiva y difícil de captar. Hoy sería como querer atrapar algo especialmente volátil. Verdaderamente un sondeo proporcionará un número. Pero ese número no representará nada. Sería como esforzarse en determinar la temperatura de Francia o la longitud de una barra de caucho estirada irregularmente.

El alineamiento de la universidad norteamericana desde 1940, referido por Blondiaux, con el método de Gallup, con las publicaciones de Cantril y Katz, así como el papel desempeñado por de Lazarsfeld en las encuestas de opinión, es ostensiblemente más difícil en Francia. Según Pierre Thionet [entrevista], las dudas y las reservas emitidas por la comisión de expertos, cuya actualidad es por otra parte destacable, no hacen sino mostrar la desconfianza de Carmille; éste concluirá en su informe al ministro de finanzas que las condiciones teóricas necesarias para que un sondeo sea legítimo, sólo se dan en la practica en situaciones extremadamente raras, y en los otros casos, no se sabría atribuir a los sondeos por el método representativo el mismo valor matemático que el que se ha podido atribuir a los sondeos aleatorios. Finalmente recuerda que un sondeo no podría ser sustituido sistemáticamente por una estadística bien hecha.

Esta desconfianza no impidió que Carmille aceptara la oferta de Stoetzel para trabajar en una sección de sondeos creada a principios de 1942 en el seno del SNS y situada bajo la dirección de un Pierre Delagrange, formado en la Escuela Central de Artes y Manufacturas. Pero las prevenciones de Carmille contra los sondeos no estaban claras: la sección de sondeos no estuvo nunca compuesta más que por $M$. Delagrange y su secretario, dice Thionet, criticando duramente una publicación sobre «las encuestas por sondeo» destinada a las administraciones, editada por ese servicio, y que retomaba las tesis de Stoetzel (ver Stoetzel, 1943). El SNS no obstante, dirige, con la ayuda de Stoetzel y de la logística de 
sus 35 direcciones regionales, toda una serie de encuestas por sondeo, fuesen aleatorias o no. La primera encargada por el Secretariado de Estado para la Producción Industrial y el Comercio, trató sobre la opinión de los franceses respecto a los intercambios de ropa usada por tickets. También se hizo una encuesta sobre las viviendas ( 2.000 encuestas) y sobre el cine (18.960 encuestas). Las encuestas sanitarias se sirvieron de ficheros muy diversos como los dosiers médicos de los Chantiers de la Jeunesse (1941), ${ }^{9}$ o los ficheros de las administraciones hospitalarias de algunas grandes ciudades (1942), incluso ficheros de los servicios agrícolas de los municipios (1941) que el SNS explota en la primera encuesta agrícola anual encargadas por el ministerio de agricultura y que continuará hasta 1944, a pesar de la baja calidad de sus resultados. En el seno del SNS se constituye una comisión que aprueba el decreto de 30 de marzo de 1944 sobre «censos aproximativos por medio de sondeos» mediante el cual, toda investigación por sondeo realizada por una administración pública u organismo privado de interés general, debería someterse a su aprobación. Como ha señalado Béatrice Tuochelay en su tesis $(1993,120)$, el SNS se beneficia de una legislación muy favorable. El encuadramiento de las personas y las actividades impuestas por las autoridades de Vichy produce una abundancia de datos administrativos y profesionales sin precedentes en la historia de la estadística pública.

\section{EXPLOSIÓN DE SONDEOS CON LA LIBERACIÓN.}

Desde el otoño de 1944, el IFOP, acogido poco más tarde por el CEGOS, retoma sus actividades bajo la forma de encuestas que se publican en la revista Sondages y en diferentes diarios que se anticipan con mediciones de la opinión. Rápidamente el IFOP sale de la clandestinidad, a pesar de la competencia del SNS. Animado por P.Copeau, P. Hervé, Y. Morandat y M. Barioux, se dota de un comité de dirección compuesto por personalidades de la universidad (G. Gurvitch, D. Lagache, H. Wallon, E. Labrousse, G. Luftalla), dispone de 160 agentes y corresponsales, y publica hasta los años sesenta en su revista mensual los resultados en bruto a las cuestiones de opinión política, que en ocasiones resul$\tan$ instructivas, aunque a menudo resultan ingenuas o de mala calidad ${ }^{10}$. Dichas cuestiones eran elegidas por el comité director o por el gobierno, y se planteaban a unas 2.000 personas.

${ }^{9}$ Organismo de educación obligatoria para la juventud durante el régimen de Vichy.

10 1945: ¿Está usted satisfecho con la manera de comportarse los militares americanos en Francia?

1947 : pregunta 126: ¿Si se le pidiera elegir entre las siguientes personalidades a quién designaría como presidente de la República: Vincent Auriol, Marcel Cachin, Yvon Delbos, el general de Gaulle, Francisque Gay, Felix Gouin, Edouard Hériot?

Pregunta 128: ¿Cuáles serían a su juicio, las principales causas de las dificultades que atraviesa el país en la actualidad?

Pregunta 130: ¿Le gustaría que las ciudades francesas tuvieran rascacielos como en América?

Pregunta 131: ¿Cuál es a su juicio la región más bella de Francia? 
En la Francia liberada, que debía reconstruir por completo el consenso político, la opinión pública era un soporte importante. También desde el punto de vista de la geoestrategia mundial, el IFOP recibe apoyo de las Fundaciones americanas que actúan en el marco de la plataforma de investigación del plan Marshall dedicada al desarrollo de las ciencias sociales y a la lucha contra el comunismo. Stoetzel, entonces profesor de psicología en Burdeos y encargado de curso en el IEP de Paris, divulga su método a través de numerosas conferencias, tanto en suelo nacional como internacional ya que encuadra su instituto en el marco industrial mundial - IAPOR que agrupa una quincena de institutos - y académico, llegando en 1947 a ser el primer presidente de la World Association of Public Opinión Research (WAPOR).

La fundación Alexis Carrel se extingue en agosto de 1944, pero su personal se incorpora al nuevo Institut National d'Études Démographiques creado por la ordenanza de 24 de octubre de 1944. El INED, creado nuevamente gracias a los esfuerzos de Robert Debré, de Adolphe Landry, de Henri Laugier y de su director Alfred Sauvy" ${ }^{11}$, toma la iniciativa de las primeras encuestas por muestreo sobre el gasto de los hogares. Efectivamente, Stoetzel y Girard se hallan a la cabeza de una sección de psicosociología que sustituye al servicio de sondeos de la ex-Fundación, y cuya principal función es organizar investigaciones sobre temas tan diversos como la movilidad social, la opinión sobre el alcoholismo, las actitudes frente al aborto, la contracepción y la inmigración ${ }^{12}$, o finalmente, los presupuestos familiares. La mayor parte de esas investigaciones se hacen mediante sondeos, pero la aproximación, recuerda Sauvy en un prefacio de 1950 a la presentación de los resultados, se hace por

el discutido método de las cuotas y las entrevistas en los domicilios. La cuestión no es saber si la muestra es o no representativa, ni si las respuestas han sido sinceras....La cuestión es saber si los resultados de la encuesta permiten tomar la decisión mas oportuna

Para Sauvy se trata ante todo de «guiar la acción pública», y en el ejemplo que él elige, los presupuestos familiares, se trataba de establecer un índice del coste de la vida con fundamentos menos discutibles que el de los presupuestostipo de antes de la guerra:

\footnotetext{
"Sauvy que había regresado a la Statistique Generale tras su paso por el Gabinete de Charles Spinasse (1936) después en el de Paul Reynauld (octubre 1938), y en el Comité de Programas y de Compras Aliadas con Jean Monnet, fue durante algunos meses Secretario General de Familia y Población.

12 «Encuesta sobre los inmigrantes italianos en Francia...sobre la posibilidad de hacer venir un número suficiente de trabajadores italianos por el reclamo de los inmigrantes ya instalados«; Los tiempos han cambiado bastante. Encuesta «para determinar la acogida que podrían tener las medidas encaminadas a atrasar la edad de la jubilación»; que vuelve a estar de actualidad.
} 
el procedimiento de muestreo aunque imperfecto, incluso no representativo, no es sólo una comodidad, sino a veces una necesidad. Ningún otro procedimiento permite, por ejemplo, aproximarse al conocimiento de los presupuestos familiares de una categoría social determinada. Las investigaciones realizadas tras la guerra en este campo han prestado importantes servicios, aunque las muestras utilizadas no fueran representativas y las respuestas estuvieran afectadas por errores sistemáticos.

Razón de más para que resulte chocante comprobar cómo el texto siguiente, en la misma publicación, es una exposición técnica (de Simone Lefevre) del método estadístico y del cálculo de errores de muestreo en los sondeos aleatorios que no practicaba el INED. Alain Girard se muestra más claro en un texto anterior de Population (Girard, 1974a) al recordar que la ley de los grandes números no se aplica sino en los límites del azar. Le parece suficiente animar a los encuestadores y dejarles encuestar en su entorno. La confianza que inspira el encuestador a su alrededor es la mejor garantía de la sinceridad en las respuestas, de ahí el reclutamiento de corresponsales poco remunerados pero motivados entre los maestros eclesiásticos y militantes sindicalistas. La entrevista personalizada con una buena dosis de empatía a la Rogers, y la recompensa cuidadosamente calculada, es un modelo psicosociológico que se articula normalmente con una selección razonada y que se opone totalmente a la fría neutralidad del sondeo aleatorio. Pero paradójicamente es el cálculo de probabilidades el que permite a Girard evaluar en 2000 el tamaño de una muestra que proporcionaría una precisión suficiente.

Si se observa con más detalle las indicaciones metodologicas de la investigación sobre gastos de 1080 familias de la región parisiense en marzo y junio de 1946 (Girard, 1947b), en la tabla de número de cuestionarios distribuidos por categoría de familia (tamaño y profesión), llama la atención que las cuotas han sido muy flexibles. En la encuesta de noviembre sobre 936 familias de militares (Girard, 1947c), los cuestionarios han sido cumplimentados por voluntarios. Y en la síntesis de las encuestas sobre presupuestos familiares de 1946, Girard admite que los 2910 presupuestos no han sido seleccionado según el principio del método representativo. A pesar de todo, estas primeras encuestas hechas en condiciones económicas difíciles permitieron apreciar la variación de los presupuestos en función de las categorías de familias (ley de Engel). El INED aunque continúa interesándose en las condiciones de vida, abandonaría pronto la observación de los gastos efectivos. No obstante, había abierto una vía y pronto correspondería a otros organismos específicos proceder al estudio del consumo de los hogares: el CREDOC (creado en 1953) y el INSEE, que contaron con medios de amplitud muy diferente y trabajaron desde otra optica, escribe Alain Girard mucho más tarde (1986). 


\section{CONSTRUCCION DE UNA COMISION DE EXPERTOS EN EL SNS}

Carmile es detenido por la GESTAPO en febrero de 1944 y muere en Dachau en enero de 1945. Bunle asegura a duras penas la interinidad en el SNS. Las Direcciones Regionales, víctimas directas o indirectas de los bombardeos funcionan al ralentí. La confusión y las dificultades del período hicieron que se suspendieran casi todas las encuestas en 1944-45 y ya nunca recuperarán el ritmo anterior $^{13}$. Para la estadística oficial, los años 1944 y 1945 estuvieron marcados por una escasa productividad y por el retroceso de la práctica de los sondeos. No obstante, una serie de demandas institucionales par parte del Ministerio de Trabajo, de Interior y de la Producción Industrial, provoca, tras la liberación, un relanzamiento de los servicios de sondeos e inmediatamente después, una reorganización completa del SNS. La ley de finanzas de 27 de abril de 1946, oficializa la creación del INSEE bajo la dirección de Francis Closon, y bajo la tutela del Ministerio de Economía y Finanzas. Los decretos de junio precisaran las atribuciones. La sección de sondeos, tras haber dependido del Gabinete, es situada en la misma Dirección que la Statistique Générale. La falta de continuidad de la labor de Stoetzel a partir de enero de 1946, se inscribe en una campaña general de reducción de efectivos, pero puede ser también por la voluntad de dejar el campo libre al equipo que se forma alrededor de Pierre Thionet y Raymond Lévy-Bruhl a finales de 1946.

El itinerario intelectual de Piere Thionet está muy marcado por las circunstancias excepcionales de la guerra. Apenas terminado su tercer año en l'École Normale Supérieur de la calle Ulm, es movilizado en septiembre de 1939, luego dado de baja temporal por problemas de salud debido a ciertas dificultades auditivas que le acompañarán toda su vida. Destinado a la Navale de Saint Louis (replegada en provincias) hasta la llegada de los alemanes en agosto de 1940, y al año siguiente en el Henri IV, no guardó un buen recuerdo de esos dos años de aprendizaje que acabaron con una solicitud de licencia. Después cursó el cuarto año (1941-42) en l'École Normale consagrado a la investigación. En ausencia de Darmois (en semi-libertad en Londres), de Dugué en Argel, al que Thionet sustituye en ciertos trabajos prácticos, nuestro «normalien» pasa el tiempo devorando la literatura anglosajona anterior a la guerra. Es entonces cuando el director de l'École le orienta hacia la estadística y Bunhle le recluta para la SGF como administrador de $3^{\mathrm{a}}$ clase. Continúa en el ISUP, y puede ser que en l'École de Application que abre sus puertas en octubre de 1942 bajo la dirección de Eugène Morice $^{14}$, los cursos de econometría de Roy, de probabilidad de Foret, de demografía de Bunle, y de mecanografía de Viennot. Pierre Thionet recuerda haber pasado por todas las secciones del SNS, incluido el Institut de Conjonctu-

\footnotetext{
${ }^{13}$ Thionet, 1947-48, p.168.

${ }^{14}$ Aunque no es uno de los cuatro alumnos de administración de la primera promoción, todos politécnicos.
} 
re con Alfred Sauvy, pero con pocos contactos directos con Carmille, excepción hecha de dos viajes a Lyon. Como bastantes estadísticos y como el propio Bunle, realiz6 una estancia de algunos meses en Alemania, en el servicio estadístico de la zona francesa de ocupación de Baden-Baden, pero es a su regreso a Francia, en noviembre de 1946, cuando comienza verdaderamente su carrera de especialista en sondeos, con la publicación de una obra innovadora sobre los métodos estadísticos de las administraciones americanas.

Este libro (Thionet, 1946) es una síntesis crítica de las experiencias americanas en materia de investigación y de la práctica de los sondeos tomados de los principales centros de investigación aplicada norteamericanos del momento como son el Bureau of Census y el State Colleage of Iowa. Dos hombres, animados por el mismo ilustrado afán de informarse sobre los métodos americanos, llegan a construir de forma paralela un grupo de expertos sobre técnicas de sondeo, único en Francia. Mientras que uno, Thionet, perfilaba en Alemania el manuscrito de una obra enteramente basada en el estudio bibliografico de las técnicas de muestreo, el otro emprendía un viaje de nueve meses, seis de cursos intensivos de estadística matemática en Columbia más tres meses en Wahington, repartidos entre el Bureau of Labor Statistics, donde se inicia en la estadística económica y social, y el equipo de Hansen Hurwitz que trabaja sobre los métodos de encuesta del Census (donde se reencuentra con Deming).

Es interesante señalar que América era entonces no sólo el país de los libertadores de la patria ocupada y de los financiadores del Plan Marshall, sino también El Dorado de todos los investigadores franceses inmediatamente después de la guerra. Los economistas (como el futuro Director General del INSEE Edmond Malinvaud) van a descubrir la econometría, la teoría de juegos e incluso la investigación operativa desarrollada por aquellos que habían huido del nazismo y de Europa en los años treinta. Alain Douard (1982) hace de la referencia a los EEUU una de las bases del auge de las ciencias sociales en Francia y da una lista de los sociólogos y psicólogos franceses - entre los que se encuentran Boirricaud, Crozier, Mendras, Touraine - que van a los Estados Unidos con una beca Ford o Rochefeller y la conciencia de un importante retraso por cubrir. Para la estadística, el ejemplo de los Estados Unidos es instructivo, como dice Thionet, porque a pesar de ser una organización fragmentada entre el Bureau of the Budget, las Agencias Federales de los Ministerios, el Bureau encargado del censo, de la producción y del comercio, y el BLS encargado de los precios y el trabajo, se han tomado muy en serio la centralización o la coordinación de las estadísticas, al menos desde 1922, por lo que el espíritu de equipo y de organización del trabajo impresionan a todos los visitantes (Mossé, 1945). La investigación teórica en estadística matemática muestra allí un avance considerable respecto al que se puede leer o encontrar en la Francia de los años cuarenta -es necesario recordar que Ronald Fisher apenas comienza a ser conocido por especialistas como Fréchet y Darmois a finales de los años treinta-, y que esta íntimamente asociado a las prácticas administrativas. No es este el caso de Francia donde reina la des- 
confianza de cara a las probabilidades y la estadística en los medios académicos, y existe una débil formación matemática entre los estadísticos de la SGF y de los militares del SNS más orientados hacia la gestión de grandes ficheros:

Por esta vía se puede prever la próxima desaparición de todo empleo del Calculo de Probabilidades e incluso de toda ciencia estadística, a la que sustituira una vasta contabilidad nacional que reconocera la inutilidad de buscar cifras aproximadas ya que se dispondrá de cifras exactas. En todo caso, la experiencia nos muestra que, al menos en la actualidad, los principales elementos de tal Contabilidad Nacional, estarían, en Francia, completamente llenos de inexactitudes...

Puede verse aquí como el pesimismo exagerado de nuestro autor sobre el futuro desarrollo de los sondeos, se atempera con otro pesimismo acerca de la calidad de la Contabilidad Nacional, muy favorable a su oficio.

¿En justicia, qué podemos encontrar en esta primera obra de Thionet? Fundamentalmente una teoría del muestreo tan elemental como la que proporciona la precisión de las muestras aleatorias de Bernoulli y Poisson, las muestras estratificadas (Neyman y Markoff), los muestreos en dos etapas (Friedmann y Wilcox), las muestras sistemáticas y por conglomerados (que emplea la noción fisheriana de correlación interclase), dando también los cálculos y ajustes en términos de costes introducidos por Neyman y Jensen. Estos temas forman la base de la teoría matemática de los sondeos que Thionet desarrollará en profundidad durante diez años en cerca de un centenar de artículos, en sus cursos de l'École d'Application (Thionet y Lévy-Bruhl, 1947-48), en los famosos números 5 y 6 de los «Estudios Teóricos» (Thionet, 1953), o aún, en su última obra con un editor alemán (Thionet, 1978) . Como historiadores, la segunda parte de su obra de 1946 nos parece más original, porque relata tres tipos de experiencias americanas posteriores a 1938 que han servido de estudios de caso a los pioneros franceses: $1^{\circ}$ ) el sondeo, realizado según una técnica de selección sistemática, sobre ciertas cuestiones particulares como complemento del censo general de la población de $1940.2^{\circ}$ ) el muestreo aleatorio estratificado de Hansen sobre el paro, y el de Eckler sobre migraciones internas. $3^{\circ}$ ) diversas técnicas de muestreos agrícolas: muestreo por cuadrículas de Jensen en Iowa, estimación de las cosechas y utilización de una muestra maestra.

Cuando Lèvy-Bruhl regresa de los Estados Unidos en septiembre de 1947, enseguida es destinado a los sondeos. Consagra el primer año a seguir los cursos de l'École d'Applications que le indica su director, y forma con Thionet un tandem que va a ser la matriz de la concepción de las encuestas por sondeo en el seno de la Dirección de Rivet, mientras que la parte operativa (vínculos con las Direcciones Regionales y los encuestadores) pronto queda fuera de su control en beneficio de la Dirección de Explotación (Chevry, asistido por Brichler y Desabie desde 1949). Ambos va a ser capaces de transferir tecnología a un programa de encuestas por sondeo, pero entre tanto, se hacen indispensables en el marco de las nuevas tareas del INSEE: al finalizar la guerra, Michel Huber (1944), y a petición 
del Consejo Superior de Estadística reconstituido, establece en el JSSP la lista de las principales lagunas e insuficiencias de las estadísticas francesas y señala, en efecto, la debilidad del sistema de encuestas. Para superar esa situación, propone:

que se inicie en Francia una gran encuesta sobre los presupuestos familiares, en cuanto las circunstancias lo permitan. Sólo esta encuesta podra proporcionar las bases para un cálculo conveniente de índices del coste de la vida.. Junto a las encuestas sobre las familias obreras, los menos favorecidos, es necesario disponer de datos sobre las familias de las clases medias, funcionarios, empleados, familias de agricultores...

Thionet explica (1947-48, p.168) que las actividades de su servicio se multiplican a partir del momento en que él obtiene en el marco de la coordinación del INSEE, la responsabilidad de verificar los cuestionarios y los planes de sondeo de los diferentes Ministerios de Demografía, de Agricultura, de Industria y de Comercio, de Trabajo, Finanzas y Colonias. Se queja de

la extrema deficiencia de nuestros medios de cálculo numérico (que) nos ha llevado a menudo a buscar métodos mecanograficos para efectuar los cálculos estadísticos que se nos ha planteado. El INSEE no posee (diciembre de 1947) calculadoras de fichas perforadas.

\section{LAS PRIMERAS ENCUESTAS POR SONDEO ALEATORIO DEL INSEE}

La primera encuesta por sondeo sobre presupuestos familiares, fue realizada en el INSEE entre abril y noviembre de 1946 por R. Rémery a petición de la Comisión superior del coste de la vida. El objetivo era suministrar los coeficientes de ponderación de los índices así como obtener una apreciación del valor cuantitativo y cualitativo del régimen alimentario en diversas categorías de población. Los cuestionarios, en forma de cartillas de cuentas, fueron distribuidos entre las familias por los encuestadores, los cuales, todavía eran en su gran mayoría exteriores al Instituto. Las familias interrogadas $(1052+1077)$, limitadas al departamento del Sena y a un nivel social inferior o igual al del obrero cualificado y el empleado subalterno fueron elegidas con la ayuda de la extracción al azar en el fichero de la Caja interdepartamental de la Seguridad Social, y de otra parte, entre los conocidos de los encuestadores, se puede hablar así, como lo hace Desabie, de sondeo parcialmente aleatorio y de una muestra que apenas puede considerarse representativa del universo de la encuesta, y menos aún del conjunto de hogares franceses.

Las primeras encuestas por sondeo realizadas en 1948 por Thionet ${ }^{15}$ y Levy Bruhl, son encuestas de mercado realizadas para la supresión parcial del racio-

\footnotetext{
${ }^{15}$ Pierre Thionet (1954) data a finales de 1947 el momento a partir del cual ha tenido la responsabilidad de las encuestas por sondeo en el INSEE
} 
namiento después de siete años de restricciones. La primera versaba sobre la compra de tejidos tanto racionados como no racionados (Thionet y LévyBruhl,1948) y se realizó a petición del Ministerio de Industria, la segunda, sobre el consumo de productos alimenticios no contingentados (Thionet y Lévy-Bruhl,1949) y se realizó a petición del Alto Comisariado de Habituallamiento. El cuestionario sobre los textiles (febrero de 1948) relativo a las compras del hogar, lo rellenaba la madre de familia, y los hogares fueron elegidos por primera vez en toda Francia, al azar, con probabilidades iguales a partir de las hojas censales de 1946 en todos los estratos de la población. Más exactamente, se hizo una extracción en dos etapas al objeto de « reducir los gastos de la encuesta »: por un lado, las comunas sacadas al azar en siete estratos definidos por el tamaño y la proporción de población agrícola, y por otro, los hogares sacados en racimos de tres y de forma sistemática (a intervalo regular) en las hojas de los hogares de esos municipios. El tamaño de la muestra, aunque limitado por motivos económicos, fue de 4.086 hogares. Una campaña de prensa y de radio exponiendo los objetivos de la encuesta antes del sondeo, permitio obtener una tasa de rechazos inferior al 5\%, y la encuesta textil permitio constatar « que al racionamiento debido a los precios había seguido un racionamiento debido a los tikets ».

A la encuesta de habituallamiento de diciembre de 1948 sobre 4.237 hogares siguió un plan de sondeos análogo, ligeramente mejorado y más complejo : una primera estratificación en dieciocho regiones, resultado de la estratificación por tamaño y tipo de municipio. En cada estrato se escogió un número de hogares a interrogar proporcional al número de hogares del estrato, y no al número de habitantes como en la encuesta de febrero. Fueron previstos hogares suplementarios para reemplazar aquellos en los que sus moradores estuvieran ausentes o rechazasen contestar la encuesta. No obstante, la necesidad de tener en cuenta los nuevos alojamientos construidos fue relegada para posteriores encuestas. En las dos encuestas, los encuestadores eran agentes de las Direcciones Generales del INSEE, salvo Paris donde fueron completadas por quince estudiantes. Estos fueron objeto de una formación oral inicial « sobre los principios de la teoría de sondeos ", y se les dieron instrucciones escritas específicas, lo cual no impidió que fuesen controlados a posteriori mediante visitas o por teléfono. Sí sabemos que el cuestionario fue minuciosamente probado y retocado después de una primera tentativa de encuesta por correspondencia considerada desastrosa (sobre encuestas voluntarias elegidas por el método de cuotas). Estamos pues, perfectamente legitimados para considerar estas dos encuestas como prototipos esmeradamente calibrados de un modelo de sondelo aleatorio que Thionet y Lévy-Bruhl siempre intentaron mejorar, defender y generalizar. 


\section{EL MODELO DE THIONET Y LEVY-BRUHL (1948-54)}

Las encuestas INDEE-INH de 1948-51 sobre presupuestos familiares, constituyen un nuevo terreno de experimentación del método de sondeos. La primera de ellas, por ejemplo Thionet y Lévy-Bruhl 1949b, data de la primavera de 1948 y está motivada por cuatro objetivos claramente delimitados: estudiar los efectos de la supresión progresiva del racionamiento sobre los gastos de la alimentación, seguir la evolución del reparto de los gastos por hogar, evaluar la repercusión de las alzas de precios y/o de salarios sobre los presupuestos familiares, y reajustar la ponderación de índices del coste de la vida. Los gastos de alimentación en diferentes publicaciones (designación, cantidad, coste, menus) y los gastos de mayor duración como el vestido o el equipamiento de la casa, son recogidos por un cuestionario rellenado por el encuestador a partir de una entrevista minuciosa en el curso de la cual anota también el estado de la vivienda. Por primera vez en este terreno, la muestra es totalmente aleatoria, extraida sobre la única base de alojamientos del censo de 1946, aunque aún restringida en 1948 a la región de París y a las familias de 0 a 3 hijos en las que el jefe de familia era asalariado o sin empleo, con un salario inferior a cierto umbral, y en una situación inferior a la de encargado o contable. Estas restricciones fueron impuestas por el nivel económico de 1000 hogares que no permitían reproducir la diversidad de estilos de vida. El trabajo fue llevado a cabo por 60 encuestadores reclutados «entre estudiantes de sociología, asistentes sociales y personal del Instituto ", número mínimo necesario dada la pesadez del procedimiento (tres visitas) y no tanto por el tamaño de la muestra. A pesar de las recompensas ofrecidas a las familias, la tasa de rechazos alcanzo el inquietante nivel del $40 \%$. Un estudio posterior sobre las causas de este rechazo, es decir, de su variación en los diferentes tipos de familias, no fue suficiente para compensar este fracaso. Para Thionet (1954) esta « mala jugada » de las encuestas arrojaba serias dudas sobre la sinceridad de las respuestas obtenidas y fue la causa esencial del abandono a comienzos de los años 50 , del método aleatorio en las encuestas de presupuestos en beneficio del método de las cuotas.

Thionet pierde la responsabilidad de estas encuestas a partir de la llegada de Jacques Desabie en un momento de auge de las encuestas de empleo (Affichard 1987), de las que contamos con una primera versión semestral fechada en 1950. Está presentada por Lévy-Bruhl (1951a y b) quien ha importado el concepto en su viaje a Estados Unidos, y más concretamente, el concepto de encuesta mensual por sondeo sobre 25.000 hogares del Censo. La encuesta por sondeo se convierte en el nuevo marco en el cual se pueden aplicar los procedimientos aleatorios. Como para las otras encuestas de este periodo, los papeles estan bien repartidos entre Pierre Thionet, quien construye el plan de sondeo, redacta las instrucciones para los encuestadores y hace todos los cálculos de precisión relativos a las estimaciones, y Raymond Lévy-Bruhl, quien se encarga de la dificil puesta a punto del cuestionario en relación con el contenido. Este último se da 
cuenta de las insuficiencias de los métodos de investigación precedentes : las encuestas trimestrales del Ministerio de Trabajo no se dirigen sino a patronos de empresas de más de 10 asalariados y no cubren todas las actividades; los ficheros administrativos de la Seguridad Social no están disponibles, y los fondos sobre desempleados están incompletos teniendo en cuenta las condiciones restrictivas que están ligadas a las indemnizaciones (por ejemplo haber trabajado durante al menos seis meses) ; el censo quinquenal es «duro, oneroso y largo de recontar». La nueva encuesta por sondeo que proponen debe responder según el modelo americano, a las exigencias de exhaustividad, bajo coste y disponibilidad. El plan de sondeo a dos niveles es, grosso modo el que fue probado en las encuestas de mercado y de presupuestos de 1948 y 1949 : estratificación en ocho grandes regiones y en diez categorías de tamaño y grado de ruralidad, con extracción al azar de un municipio, con probabilidad proporcional al número de sus hogares (con ayuda de la tabla de Tippett), luego extracción sistemática de hogares en las hojas de la DR correspondiente al municipio, sobrerepresentando los municipios urbanos con una tasa de entrevistas más elevada para tener en cuenta la mayor heterogeneidad de comportamientos, completando por primera vez los hogares del censo con una muestra de nuevos alojamientos. Todos los individuos de más de 14 años fueron entrevistados. Los trabajos fueron realizados por los 149 encuestadores del INSEE apoyados por 11 estudiantes previamente instruidos. Se realizaron controles y los hogares a entrevistar fueron advertidos por correo, aunque los intentos de publicidad a través de la prensa y la radio fueron abandonados desde la segunda encuesta. Pero lo que permitió en 1950 bajar la tasa de no respuestas por ausencia o rechazo, a un modesto $13 \%$, fue el hecho de que se decidiese de forma imperativa entrevistar al ocupante del hogar seleccionado en el momento de la entrevista con el coste de 2, 3, y hasta 4 o más visitas. La sustitución no se hizo por ponderación sino por simple duplicación de cartas mecanográficas sacadas al azar en el estrato deficitario. Por fín si la muestra (tamaño 5700) es totalmente renovada entre las dos encuestas de 1950 , enseguida se decide no realizar sino la renovación parcial. Ciertas cuestiones también son ligeramente modificadas para poder estudiar experimentalmente los impactos de la formulación. Estas medidas así como la generalización de un plan de sondeo supone la realización de numerosas encuestas a comienzos de los años 1950, marcando el final de un periodo de puesta a punto que inaugura una suerte de standarización del procedimiento.

A pesar de las dificultades encontradas en la encuesta de presupuestos familiares, Thionet acerto a construir un plan original de muestreo aleatorio en dos niveles (municipios extraidos al azar, hogares extraidos sistemáticamente) con estratificacion de los municipios por regiones y categorías, lo cual es común a numerosas encuestas sobre el mercado del calzado (1953) y de los seguros (1953). Dejemos, no obstante, explitar a Thionet (1954) lo que de original tiene este modelo :

Este método es matemático, es decir, se presta a la correcta aplicación del calculo de probabilideades. Pero ahora que el método del Bureau of Census con- 
siste en sacar al azar pequeñas muestras, el método del INSEE, como el del Social Survey británico, se basa en la extracción al azar de direcciones en los ficheros, o sobre listas preestablecidas. La diferencia esencial entre el procedimiento del INSEE y el del Social Survey es que la administración británica está en condiciones de facilitar al Social Survey listas de direcciones adaptadas al objetivo deseado, mientras que en Francia, después de haber ensayado (Encuesta de Empleo $2^{\circ}$ semestre 1951 y Encuesta de hogares 1952) la extración al azar en los cuadernos de la administración de Contribuciones Directas, el INSEE ha preferido limitarse al empleo de la documentación personal : las hojas de hogares del censo de 1946 completadas por una muestra de nuevos alojamientos (gracias a la información obtenida de los permisos de construcción)

- La estandarización del método encuentra su punto clave en la noción de muestra-matriz introducido en el momento del censo de 1945. Tal muestra matriz constituye una suerte de inversión ( en el sentido de Thévenot) que multiplica la eficacia del método definiendo de una vez por todas la lista de distritos que servirán de primera etapa en todas las encuestas de 1954 a 1960 , no se renueva más que la extracción de municipios y de hogares. La primera encuesta INSEE-CREDOC de 1956 sobre presupuestos familiares (CREDOC, 1960) se beneficiará de la aparición de la encuesta de empleo y de la nueva base que constituye el último censo, para reintroducir con fuerza el sondeo aleatorio en un dominio que había sido abandonado en beneficio del método de las cuotas. La encuesta toma por primera vez todos los consumos de los hogares, de todas las categorías, sobre todo el territorio. Contempla mejor los agregados de la Contabilidad Nacional, permite la estimación econométrica de las elasticidades de precios y rentas, y facilita un marco a ciertos estudios de mercado. Se eligieron 22.800 al elegidos al azar en tres niveles - distritos, municipios, hogares-, y trescientos entrevistadores invitarán a los entrevistados a rellenar una libreta de cuentas muy compleja en diferentes periodos. La encuesta era pesada pués se traduce en tres visitas y 45 tipos de.tarjetas diferentes para un mismo hogar, de hecho, la encuesta de 1956 no cumplió todas las expectativas en materia de precisión de estimaciones, a menudo por razones independientes del plan de sondeo, y al hecho de que el total de gastos sobrepasase el total presupuestado, fue vivido como un relativo fracaso. Pero el modelo de sondeo estaba ya presentado y apenas iba a ser modificado hasta el censo siguiente.

De todos modos, la concepción de esta encuesta INSEE-CREDOC a pesar de estar inspirada en el trabajo de Thionet y Lévy-Bruhl, ya no era de su reesponsabilidad. Pierre Thionet había dejado el servicio de sondeos del INSEE a petición propia y por razones personales en 1954. Fue acogido en una oficina del Servicio de Estudios Económicos y Financieros montada por Gruson, donde da la impresion que, fuera de sus numerosas notras de lectura, trabajo esencialmente con Nataf y Darmois en la preparación de su tesis sobre las nociones de precisión y de información en relación con los sondeos, tesis que leerá en 1958. La continuación de su carrera profesional es universitaria y transcurre en Poitiers desde noviembre de 1960, luego en Paris-Dauphine entre 1968 y la jubilación, 
una trayectoria consagrada a la enseñanza de la estadística y a la investigación sobre la teoría de encuestas, seguida con fervor a pesar de la ruptura total y definitiva con los trabajos aplicados del INSEE. En cuanto a Raymond Lévy-Bruhl, éste dejá también el servicio de encuestas para ir al Ministerio de Trabajo a asumir la responsabilidad de la encuesta sobre asalariados y condiciones de empleo (Lévy-Bruhl, 1977). Desde entonces es sobre Jacques Desabie sobre quien debe descansar la teoría y la práctica de los sondeos (Desabie,1965) y más particularmente, las encuestas sobre condiciones de vida en los hogares (Desabie,1987).

Pero no podemos terminar con la obra del tandem Thionet-Lévy-Bruhl sin elevarnos un poco por encima de su innovación, y evaluar la extensión y recepción de sus trabajos más allá de las encuestas del INSEE del periodo 1948-54. La primera de estas extensiones es la enseñanza; Thionet enseña la técnica de la encuesta por sondeo aleatorio en la escuela de aplicación del INSEE desde 1943 a administradores y colaboradores, llegando a ocupar interinamente la dirección de la Escuela. En estos primeros años, su docencia se interrumpe en varias ocasiones por problemas de salud y por un viaje a Alemania. El curso de 1947-48, se publica como Théorie et pratique des sondages, está también firmado por Lévy-Bruhl, quien ha redactado las dos últimas lecciones más descriptivas sobre «la encuesta verbal» y sobre «los sondeos en los Estados Unidos». Trufado de ejemplos y de contraejemplos tomados de Francia y de los Estados Unidos, es la primera presentación didactica de la teoría de encuestas que se puede encontrar en Francia ${ }^{16}$. Encontramos también a los dos colegas asociados con Hansen y Yates en una publicación de un efímero Centro Europeo de aplicación estadística agrícola y demográfica creado por Darmois bajo los auspicios de la ONU, la UNESCO y la FAO y del gobierno francés. Están encargados de la formación de su personal en sondeos aplicados a la agricultura. Hay que hacer notar a este respecto que este campo de la agricultura es sobre todo de los americanos más que de los franceses, y Lévy-Bruhl que recuerda haber enseñado el pesaje de remolacha en la Ecole d'Application, siempre ha remarcado la escasez de medios del Ministerio de Agricultura durante este periodo ${ }^{17}$. Darmois está igualmente en el origen de la traducción de la obra de Yates (1949) en la que participaron Thionet y Lévy-Bruhl.

¿Como evaluar estos trabajos pioneros? Desde el punto de vista de historiador más que de experto técnico, no se deben medir con el mismo rasero las mejoras, o incluso las revoluciones, que se producirán a continuación de sus trabajos, sino que debemos evaluar las opciones que introdujeron en la estadística oficial apoyandose sobre los materiales de una época que testimonian las condiciones, los riesgos, los éxitos y controversias.

\footnotetext{
${ }^{16}$ Su curso será retomado por M.Chartier después de 1954.

${ }^{17}$ Encontramos, sin embargo una participación de Thionet en la encuesta anual de salarios de la agricultura realizado por sondeo a partir del censo y de los ficheros de las Cajas de Seguros Sociales, así como sobre el modelo de encuestas hwechas por el ministerio de Trabajo. El documento de síntesis (Thionet 1954b) contiene bajo la forma de resúmenes de las instrucciones a los encuestadores, un lujo de detalles sobre la elaboración de la tasa de sondeo.
} 


\section{EVALUACION: LOS BENEFICIOS Y LAS PERDIDAS DEL AZAR}

La primera de todas estas opciones sería la del sondeo frente la de los grandes ficheros del SNS y de la contabilidad nacional. Pero hemos visto que esta opción flota en el ambiente para una gran número de investigaciones privadas o públicas y que para la estadística pública no es incompatible con las otras dos, ya que el hecho mismo de elegir el muestreo al azar obliga a apoyarese sobre una base de sondeo eshaustivo y fiable.

La opción principal es, por tanto, la del azar, tomada en contra del método de la elección zazonada. Thionet remonta la responsabilidad al SNS de 1942 y a Carmille, aunque da la impresión de que las cosas no fueron interrumpidas hasta la marcha de Sauvy y Stoetzel al INED. El método de sondeo aleatorio es afirmado de manera cerrada y regular por Thionet y Levy-Bruhl contra el «método Gallup» de sondeo por cuotas defendido por Sauvy, Stoetzel y Girard. Si este último dice en 1986 que «la polémica está hoy sobrepasada», reconoce que fue viva también en el interior del INED donde no escaseaban los matemáticos abiertos a la estadística matemática ya que en el interior del INED y el INSEE, la creación misma de los centros y las atribuciones que les fueron conferidas constituyeron el gran eje de un proyecto científico del equipo formado en la Fundación Carrel, marcado por la idea de la ciencia social unificada. A pesar de los textos estatutarios que invitaban a la cooperación y al reparto de medios, la situación de casi monopolio del INSEE fue amargamente criticada en numerosas ocasiones por el INED, ya fuese en terminos de medios financieros y mecánicos, o en términos de atribuciones legales, como la obligación de los encuestados de responder, y el secreto estadístico que le sirve de contrapartida, o incluso el monopolio del visto bueno necesario a toda encuesta bajo cobertura del comité de coordinación (Girard 1986,76). La elección del sondeo aleatorio o del sondeo razonado es también, en efecto, una cuestión económica antes que una cuestión científica: es por el argumento del coste en función de un nivel de precisión dado, o al contrario, de la precisión en función del coste, por lo que los estadísticos prefirieron la primera de estas dos opciones. Posiblemente los sicologos del INED optaron por la segunda posibilidad porque necesitaban una base de sondeo y de encuestadores numerosa, más dispersa y de mejor formación. La cuestión del coste va a ser central como revelan los ataque continuos de Stoezel o Sauvy sobre el tema ${ }^{18}$. Por su parte, Thionet y Levy-Bruhl no desaprovechan una

${ }^{18}$ Por ejemplo en la discusión de la exposición de Lévy-Bruhl en la Sociedad de Estadística de Paris (Lévy-Bruhl 1951) : «-M.Rivet rinde homenaje a sus colaboradores....

- M. Stoetzel se une a M. Rivet para felicitar al conferenciante y preguntarle sobre el coste aproxomado de un encuesta de ese tipo.

- M. Lévy-Bruhl los evalúa aproximadamente en $\mathbf{5 0 0 . 0 0 0 ~ f r a n c o s ~ p o r ~ l o s ~ g a s t o s ~ d e ~ d e s p a l z a - ~}$ miento y en 2.000.000 por las horas de trabajo de los encuestadores (...) M. Thionet precise que en su opinión el trabajo de los administradores represente un gasto de alrededor 500.000 francos.

- M.Stoetzel emite el deseo que cuando un estudio estadístico sea presentado, sea necesario presentar el coste ( no dirá otra cosa en la discusión) 
ocasión para criticar el debil valor científico de «el método Gallup». Desde 1945, Thionet se ha labrado una reputación de especialista de esgrima, en una bella controversia con Galvani a propósito de los méritos de la escuela italiana y de su lider Corrado Gini, le describe como «intransigente», «eterno batallador contra las teorías anglosajonas» con «un sentido muy vivo de la demanda », testimoniando «un profundo desprecio por sus grandes rivales». No creemos que haya pensado mejor de Stoetzel. Los dos son, en todo caso, representantes de una estadística sin la matemática y sin la probabilidad que condena ${ }^{19}$. Solo el método aleatorio es matemático y se presta a la aplicación correcta del cálculo de probabilidades, dice en diferentes lugares $(1947,1954)$. Lévy-Bruhl escribe todo un artículo en el JSSP (Lévy-Bruhl,1951c) para burlarse del último fracaso de Gallup : si se conoce el asunto de 1936, aunque se recuerda menos su previsión erronea acerca del triunfo de Dewey sobre Truman en las elecciones presidenciales de 1948 y del descrédito que le supuso.

Gallup y sus colegas se convierten en objeto de bromas no solo de la prensa sino del conjunto del público. Es así, por ejemplo que el día que Truman asume oficialmente las funciones de Presidente en Washington, en el Senado del Estado de Indiana, todos los senadores por unanimidad observaron de pie, un minuto de silencio a la memoria del Doctor Gallup.

Más allá de las tácticas bélicas que representan las burlas, nuestro autor analiza las características del método que indican un defecto del aparato de medida

Parece que la técnica utilizada por los Institutos de Opinión Pública puede introducir errores sistemáticos no medibles. Da la sensación, por tanto, que el método utilizado pudiera ser tenido por responsable del error total»

La posibilidad de un cálculo del error es, por supuesto, la gran ventaja del método aleatorio sobre el método de las cuotas, el cual reduce el error por elecciones razonadas sin conocer el grado final de aproximación. Ciertamente se trata, $\tan$ solo del error de muestreo, y Thionet no cesa de recordar que hay que añadir los errores propios de toda investigación empírica, por ejemplo: errores sobre el objeto, errores ligados al parato de medida, al observador, etc.

${ }_{19}$ Su divisa, en lugar de ser «Estadística con matemáticas» debería ser «Estadística con el mínimo de matemáticas» (J.R.S.S. 1926,706-7) Nosostros no sabriamos compartir una concepción parecida porque, si ella significa, como es en efecto el caso, que la mínima fórmula de Cálculo de Probabilidades es una falta, mientras que Gini se permite formulas de algebra muy elementales espantosamente complicadas e inutiles, se puede verdaderamente hablar entonces de espiritu de sistema, pero esta extrema desconfianza de nuestro autor a la vista de toda hipotesis suplementaria y gratuita, de todo esquema (sobre todo probabilista) caracteriza verdaderamente sus trabajos y su escuela (JSSP,1945,250)

${ }^{20}$ Indeterminación del universo a encuestar, indeterminación de la información deseada, fluctuación física, errores de redacción del cuestionario, errores en las respuestas, segos del entrevis- 
Levy-Bruhl (1949) lista una docena de causas de error $^{20}$ para el caso de encuestas con cuestionario. Pierre Thionet desarrollo el cálculo del error desde un punto de vista teórico en su curso de 1947-48, pero el análisis del error total asociado a un sondeo es todavía hoy, muy delicado. En la práctica, las cosas son muy complejas porque no todo es calculable, pero el esfuerzo del que da prueba por adaptar estos cálculos a los casos de sondeos más complejos, es remarcable. Incluso la visita repetida de encuestadores es explotado para calcular la desviación debida a los no-respuesta. Todavía es más de agradecer esa voluntad de publicar los cálculos del error para cada una de las encuestas, lo que hace explicitamente para la encuesta de empleo a partir de 1951: aparece en el BMS un anexo a la presentación de la encuesta, que esta consagrado a la estimación y la discusión sobre la precisión de los resultados, expresados en términos de coeficientes de variación del número total de horas trabajadas (variable según las regiones entre el $2 \%$ y el $15 \%)$, o del número de parados $(10,6 \%)$. La síntesis presentada en 1954 a la SSP trata, sobre todo, de la evaluación de errores de muestreo en las encuestas realizadas con dos niveles de sondeo.

Lo ideal sería poder publicar juntos los resultados de la encuesta y los cálculos del error. Desgraciadamente, esto retrasaría notablemente la publicación de los resultados, y ha sido necesario renunciar renunciar a ello de una vez por todas en el INSEE. Los cálculos de error son entonces efectuados en los tiempos muertos, tanto en la parte mecanográfica como en la parte manual del trabajo (...) Para terminar formulamos el voto para que investigaciones similares puedan ser efectuadas a propósito de nuevas encuestas en el INSEE ; nosotros deseariamos que se den cuenta de la absoluta necesidad de este género de especulación (para una administración que pretende emplear métodos cientificos) y que en consecuencia se consagren los medios necesarios (Thionet 1954,184-195)

Da la sensación de que estas voces devotas pero razonables, no han sido comprendidas, y que se haya considerado toda esta actividad de cálculo de Thionet como una especie de manía de matemático, una especie de lujo que no tenía más consecuencias y que la renuncia que él señala ha perdurado hasta alcanzar a todas las publicaciones de cualquier cálculo de error. No es la menor de las paradojas, ver una decisión justificada por la única razón de que era el único en justificar el cálculo de error. La reciente crisis de confianza hacia los sondeos políticos ha puesto al día esta necesidad de calcular las estimaciones de una medida de error, $y$ algunas tímidas iniciativas se han hecho eco de lo expresado por Thionet hace ya 50 años. Pero la pesadez de los cálculos no es la razón pricipal de esas renuncias que todavía se mantienen.

tador, interacción encuestador-encuesta, campo de la encuesta mal cubierto, influencia del organismo encuestador, mala redacción de las instrucciones, mala transcripción en las tablas, sesgo de interpretación de los resultados. 


\section{BALANCE : LA ELECCION DE LA UNIDAD ESTADISTICA.}

Esta primera faceta de la controversia, oculta otra que tal vez sea más importante de lo que parece, como es la elección de una unidad estadística privilegiada. Es claro que los investigadores del INED se asoman sobre toda una serie de problemas muy variados que incluyen hechos, opiniones, gustos, deseos, orientación profesional, salud, higiene, natalidad, inmigración, etc. para los cuales, la unidad significante es el individuo, ya sea a nivel de disposiciones, de opiniones o de decisiones y de acciones; incluso si sus sentimientos natalistas y sus profesiones de psicosociólogos, les conducen a situar estos acontecimientos en el marco de la familia o del grupo social. Las preocupaciones y atribuciones del INSEE le hacen, por el contrario, privilegiar a priori los actores económicos, y sobre todo los gastos del hogar. Qué esta lógica institucional sea repetida por razones prácticas e históricas, reenvía a los trabajos de Thionet. Es también el punto que le aleja del modelo americano, al elegir, más que el sondeo aleatorio del Censo, una extracción al azar de direcciones de viviendas, y ello porque es la forma práctica de unidad censal ya que habiendo ensayado en vano, dice, trabajar con los ficheros de otras administraciones este sistema ha revelado ser el más eficaz. Solo resta definir el hogar como conjunto de personas que comparten el mismo alojamiento (a diferencia de la familia que interesaba al demógrafo, o del hogar que interesaba al contable nacional), y preveer un último nivel de sondeo (en general con una extracción exhaustiva, o más tarde el «Kish», que Lévy-Bruhl ha introducido teóricamente en Francia) para aquellos individuos a los que se les hubieran asignado preguntas específicas. Pero esta elección es evidentemente un compromiso, es decir, un punto de debilidad del sondeo aleatorio que los partidarios de Gallup no dejan de explotar (por ejemplo en la discusión de Lévy-Bruhl, 1951), diciendo por un lado, que el efecto racimo de este sondeo tiene dos niveles: hogares e individuos, y que debilitará la precisión de los resultados en caso de fuerte correlación intra-racimo. Thionet se defiende con el argumento de que en la mayor parte de los casos esta correlación es débil, también diciendo que los estadísticos no construyen muestras representativas de individuos $\mathrm{y}$, por tanto, no pueden responder correctamente a cuestiones que conciernen a los hechos individuales. En efecto, es patente que esta elección del método ha determinado de rebote, una selección de los temas y campos de encuesta, al menos para el período estudiado. La exclusión de los solteros al comienzo de las encuestas de presupuestos familiares, y la de los individuos que pertenecía a hogares colectivos (militares, religiosos...), no está siempre justificada por el fondo sino por la forma. La forma hogar como unidad estadística, ha privilegiado en los presupuestos familiares el estudio de gastos de alimentación y alojamiento a expensas de otros gastos como el vestido, salidas y vacaciones, así como el consumo exterior al alojamiento. Esta misma formula ha impuesto una figura intermedia (la «madre de familia», «el jefe del hogar») entre el consumidor final de bienes y servicios y el estadístico (CREDOC,1960) lo que no 
ha hecho sino degradar la calidad de la información. La elección del hogar como unidad estadística fue particularmente inadecuada para las encuestas de presupuestos, y se intuye que no siempre fue óptima en las encuestas de empleo.

Si se considera que la standarización de estos planes de encuestas, llevado a cabo después de 1950, ha podido inducir el caracter uniforme de la metodología y su autonomización como « forma », podemos preguntarnos si la industrialización del procedimiento resultante no ha reducido seriamente la flexibilidad original de la encuesta por sondeo, y ha reducido a la nada toda posibilidad de adaptar esta técnica a nuevos objetos de encuesta que aparecen en la agenda de quienes toman las decisiones políticas como la mejor evaluación del consumo, del paro, etc. que, tal vez, necesitaba eliminar la lógica del " hogar ". Por otra parte, la representatividad de la muestra al azar no es siempre una necesidad absoluta, y algunos investigadores (del CREDOC, por ejemplo) han mostrado que, al contrario, era necesario aplazar la exigencia de representatividad y optar por la sobrerepresentación de ciertas categorías en proyectos de investigaciones comparativas o heurísticas que no interesaban por las estimación de medias y proporciones sino a efectos cualitativos de oposiciones o de encadenamientos del comportamiento. El sondeo aleatorio no es forzosamente la panacea.

\section{CONCLUSIÓN}

Dejaremos a estudios anteriores (Desabie,1987 ; Glaude,1996 ; Desrosières,1996) o por llegar, el cuidado de responder a la cuestión de una posible esclerosis del método y de su capacidad para evolucionar en el futuro. Conviene recordar además, que el futuro normal y deseable de toda innovación técnica es que se estandarice para industrializarse, aunque dicho proceso también debe ponerse en cuestión ya que la standarizacion impide toda evolución y toda adaptación a las nuevas necesidades.

Este breve episodio que hemos evocado ha jugado ciertamente un papel importante en la metodología de la encuesta que se configura durante medio siglo. Sin duda está marcado por las condiciones de la post-guerra mundial: contexto de una reconstrucción apoyada sobre el relanzamiento del consumo y la ayuda americana, la emergencia de disciplinas económicas (Armatte, 2003), el desarrollo de las ciencias sociales (Drouard,1982), la puesta en funcionamiento de nuevas instituciones del Estado, el papel de los ingenieros estadísticos (Desrosieres 1994), los nuevos desafíos planteados a las encuestas por la introducción de la contabilidad nacional y la modelización macroeconómica (Armatte y Desroasieres 2000), etc. Durante los años cincuenta, la encuesta se convierte en un dispositivo fundamental en la reconstrucción del Estado del Bienestar y en la deriva posterior hacia el Estado-empresario : puesta al servicio de la Contabilidad Nacional, la encuesta permite establecer previsiones a corto plazo y realizar la planificación en el medio plazo sobre bases empíricas, constituyendo el cua- 
dro de navegación indispensable para el manejo razonado de la política económica. Esta innovación que constituye la encuesta por sondeo participa de todo un sistema complejo de regulación económica y social que domina los Treinta Gloriosos años y no debe reducirse a la mera consideración de una invención técnica. Rindamos, en consecuencia, un último homenaje a la persona de Pierre Thionet porque supo transformar esta invención en innovación, porque supo batallar para no disociar jamás las exigencias científicas de las económicas, a menudo constrictoras pero necesarias, en el esfuerzo de reconstrucción y en el espíritu de servicio público. Incluso si perdio algunas batallas, incluso si las que gano son, a menudo, conquistas amenazadas.

\section{REFERENCIAS BIBLIOGRÁFICAS}

AfFichard J. (1987), L'enquête sur l'emploi, Pour une Histoire de la Statistique, tomo 2. Paris, INSEE.

ANTONELli A. (1921), Une enquête régionale sur le coût de la vie, Revue d'Économie Politique, 19.

ARMATTE M. (1988), La construction des notions d'estimation et de vraisemblance chez Ronald A. Fisher, Journal de la Société Statistique de Paris, tomo 129, № 1-2, 1988, reeditado en Estimation et sondages, J. Mairesse ed., París, Economica.

ARMATTE M. (1995), Histoire du Modèle Linéaire. Formes et usages en Statistique et en Économétrie jusqu'en 1945, Tesis doctoral, dir. Jacques Mairesse, EHESS, 1995. 970 p. Chap. 12.

ARMATte M. (2003), «Les sciences économiques et la pax americana », en Pestre \& Dahan (eds). Les seciences dans et pour la guerre,1940-1960, París, Presses de l'EHESS.

ARMATTE M. y, DESROSIERES A. (2000), Méthodes mathématiques et statistiques en économie: nouvelles questions sur d'anciennes querelles, en J.P. Beaud et J. G. Prevost (eds.), L'ère du chiffre, systémes statistiques et traditions nationales. Montréal, Presses Universitaires du Québec, 431-481.

Blondiaux L. (1998), La fabrique de l'opinion. Une histoire des sondages. París, Le Seuil.

BoARD OF TRADE (1909), Cost of living in French towns. Londres, Darling \& Son.

Bowley A. L. (1901), Elements of Statistics, King and Son, London. $2^{a}$ ed. 1902, 335 p.; $4^{a}$ ed. 1920, 454 p.; Traducción francesa de la $5^{\mathrm{a}}$ edición por L. Suret et G. Lutfalla, 1929.

Bowley A. L. (1906), Presidential Adress to the economic section of the British Association. JRSS, 540-.558.

BowLEY A. L. (1926), Measurement of the precision attained in sampling, Bulletin II.S., XXII-I.

BRU B. (1988), Estimations Laplaciennes, JSSP, 129, 1-2, 1988, et Mairesse (ed.), 1988. $7-46$.

CREDOC (1960). La consommation des ménages françaís en 1956, Consommation, VII2, (avril-juin). París, Dunod.

DARMOIS (1948). Statistiques mathématiques, Lecciones impartidas en l'École d'Application en 1937-:38, 1944-45, 1947-48, et compilado por $P$. Thionet, INSEE. 
DELPECH H. (1938), Recherches sur le niveau de vie et les habitudes de consommaton (Toulouse 1936-38). París, Sirey.

DEMING W.E. (19.50), Some Theory of Sampling. New York, Wiley.

DESABIE J. (1965), Théorie et practique des sondages. París, Dunod.

DESABIE J. (1987), Les enquêtes sur les conditions de vie des ménages, en Pour une histoire de la Statistique, tome $2^{\mathrm{a}}$, ed. J. Affichard, París, Economica, INSEE, 253-286.

DESROSIĖRES A. (1988), La partie pour le tout: comment généraliser? la préhistoire de la contraínte de représentativité, en Estimation et sondages, J. Mairesse ed. París, Economica.

DEsRosières A. (1994), De l'École de l'INSEE a l'ENSAE et l'ENSAI: 1942-1994. Éléments d'histoire d'une école de statistíque et d'économie, Conférence ICOTS4. Marrakech, Publ. I.I.S.

DESROSIĖRES A. (1996), Essai sur l'évolution des usages des énquêtes sur les budgets de familles 1850-1970, en L'évolution des enquêtes «condition de vie» de l'INSEE du IXeme siecle a nos jour, INSEE (cincuentenario).

Desrosières A. (2000), La politique des grands nombres. Histoire de la raison statisti$q u e, 1^{a}$ ed. $1993,2^{\mathrm{a}}$ ed. 2000 , París, La Découverte.

DIDIER E, (2001), Les premiers sondages americains, naissance de la représentativité et démocratie, dans Enquêtes, modeles et applications, J.J. Droesbeke et L. Lebart. París, Dunod, 29-43.

Drouard A. (1982), Réflexion sur une chronologie: le développement des sciences sociales en France de 1945 a la fin des années soixante, Revue Française de Sociologie, 55-85.

DroesBeKe J.-J. et LEBART L. (2001), Enquêtes, modèles et applications. París, Dunod.

DrouARD A. (1983), Les trois âges de la Fondation française pour l'étude des problèmes humains, Population, XXXVIII, 6, 1017-1047.

DUGE DE BERNONVILLE L. (1916-1917), Enquête sur les conditions de la vie ouvrière et rurale en France en 1913-1914, Bulletin de la S.G.F., tomo IV, 1916, 85-108; $1917,185-221$.

FIENBERG S.E., TANUR J.M. (1996), Reconsidering the fundamental contributions of Fisher and Neyman on experimentation and sampling, International Statistical Review, 64, 237-253.

GiNi C. (1928), Une application de la méthode représentative aux matériaux du dernier recensement de la population italienne (1 er décembre 1921), Bulletin I.I.S., XXIII2, 198- 215.

Girard A. (1947a), Sondages et Démographie. Population, 273-282.

Girard A. (1947b), Les Conditions d'existence des familles. Les dépenses de 1080 familles en mars et juin 1946, Population. 245-266.

GIRARD A. (1947c), Les Conditions d'existence des familles. Les dépenses de 939 familles de militaires en novembre 1946, Population, 421-449.

GiRARD A. (1948), Les Conditions d'existence des familles. Les budgets familiaux en 1946, Population, 245-266.

Girard A. (1986), l'Institut National d'Etudes Démographiques. Histoire et Développement. París, INED, $253 \mathrm{p}$.

Glaude M. (1996), Les enquêtes budget de famille des années 1960 a nos jours, dans

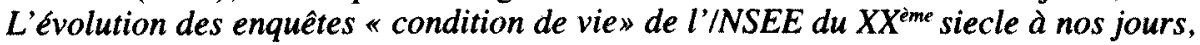
INSEE (cincuentenario). 
HalbWaChS M. (1913), La classe ouvriere et les niveaux de vie, recherches sur la hiérarchie des besoins dans les sociétés industrielles contemporaines. París, Alcan.

HANSEN M.H., HURWITZ W.N., MADOW W.G. (1953), Sample Survey Methods and Theory. New York, John Wiley and Sons.

HuBER M. (1944), Principales lacunes et insuffisances des statistiques françaises, $l S S P$, 219- 231.

INSEE et CREDOC (1960), La consommation des ménages français en 1956, Consommation, VII, avril-juin 1960, N². París, Dunod.

JENSEN A. (1926), Report on the representative method in statistics, Bulletin I.I.S., XXII, 359-377.

KIAER A.N. (1895), Observations et experiences concernant des dénombrements representatives, Bulletin de l'IIS, IX-1, 176-183.

KRuSKal W.H. et Mosteller F. (1980), Representative sampling, IV: the history of the concept in statistics, 1895-1939, International Statistical Review, 48, 169-195.

LETELLIER G. (1949), Dépenses des chomeurs et valeur énergétique de le l'alimentation. París, Sirey.

LEVY-BRuHL R., THIONET P., HANSEN H., YATES F. (1949), Sondages en Agriculture, Centre Européen d'Application Statstique Agricole et Démographique. Paris, INSEE.

LEVY-BRUHL R. (1951a), Enquêtes récentes par sondage sur l'emploi; avec discussion, lSSP, 108-125.

LEVY-BRUHL. R. (1951b), Une enquête par sondage sur l'emploi, Supplément au BMS, janv-mars, p.1. Seconde partie «Erreurs d'échantillonnage» (par P. Thionet.), avril-juin.

LEVY-BRUHL. R. (1951c), Les sondages d'opinion et l'échec des prévisions electorales de Gallup en 19-18, lSSP, 92, 63-70.

Levy-Bruhl R. (1977), Souvenirs de la période 1945-1960, en Pour une Histoire de la Statistique. tomo 1. Paris, INSEE.

LiE E. (2001), The Rise and Fall of the Sampling Surveys in Norway, 1875-1906, en Sampling humans, Preprint 166, Max-Planck-Institut.

MAIRESSE J. (ed). (1988), Estimation et sondages, cinq contributions a l'histoire de la statistique. Paris, Dunod.

MARIE G. (1945). Nécrologie de René Carmille, ISSP, juillet-aout.

Mespoulet M. (2000), Du tout à la partie: l'âge d'or du sondage en Russie (18851924), Revue d'études comparatives Est-Ouest, 31-2, 5-49.

MORICE E. (1945). Les méthodes statistiques modernes et leur expérimentation à l'expérimentation agricole. Paris, INSEE, Études théoriques, $\mathrm{N}^{\circ} 1$.

MOSSER R. (1945). La Statistique aux Etats-Unis, lSSP, 213-218.

NEYMAN J. (1934). On the two different aspects of the representative method: the method of stratified sampling and the method of purposive selection, I.R.S.S., 97,558-606.

O'MuIRCHEARTAIGH C. y WONG S.T. (1981), The impact of sampling theory on survey sampling practice: a review, Bulletin I.I.S., tomo XLIX-I.

PORTE J. (1954), Une enquête par sondage sur l'auditoire radiophonique, Supplément $B M S$, janv.-mars, p. 31.

REMERY R. (1948). Budgets de famille de salariés de la région parisienne en 1946, Bulletin de la $S G F$, Avril-juin, p. 155.

REMPP J.M. Historique des enquêtes françaises sur les dépenses des ménages, Document INSEE. 
S. G. F. (1919), Condition de la vie ouvriere et rurale en France en 1913-14. Paris, Alcan, $100 \mathrm{p}$.

SAUVy A. (1949), Statistique et conjoncture économiques, Cours a l'Institut d'Études Politiques 1948-49. Paris, Centre de documentation universitaire.

Sauvy A. (1950). Cinq enquêtes sociales. Préface, Travaux et documents, N9, INEO, 7-16.

SENG Y.P. (1951), Historical survey of the development of sampling theories and practice, IRSS, 214-231.

Stoetzel J. (1943), Théorie des opinions. Paris, Presses Universitaires de France; compte-rendu par J. Bourgeois, ISSP, 1944, 41-46.

TASSI P. (1988), De l'exhaustif au partiel: Un peu d'histoire sur le développement des sondages, dans Estimation et sondages, J. Mairesse (ed), Paris, Economica, 117-133.

ThIONET P. et HEISCH M. (1954), L'enquête annuelle par sondage sur les salaires et la main-d'reuvre salariée permanente eh agriculture, Supplément BMS, avril-juin, p.1.

Thionet P. et LeVY-Bruhl R. (1947-48), Théorie et pratique des sondages. INSEE, École d'Application, $193 \mathrm{p}$.

Thionet P. et Levy-Bruhl R. (1948), Une enquete par sondage sur le marché des textiles, Bulletin de la $S G F$, juillet-sept, p. 250.

ThIONET P. et LEVY-BRUHL R. (1949a), Une enquete par sondage sur le ravitaille ment, $B S G F$, p. 162.

Thionet P. et Levy-Bruhl R. (1949b), Premiers résultats concernant les dépenses des familles de salariés de la région parisienne au printemps $1948, B S G F$, p. 37.

Thionet P. (1945), L'école moderne des statisticiens italiens, ISS?, 245-255. Réponse de L. Galvani dans le ISS?, 1947, 196-208.

ThIONET P. (1946), Méthodes statistiques modernes des administrations fédérales aux Etats- Unis. París, Hermann.

ThIONET P. (1947), Rapport sur les sondages du 7 mai, Archives INSEE.

THIONET P. (1953), La théorie des sondages. INSEE, Études théoriques, $\mathrm{N}^{\circ} 5$.

ThIONET P. (1954a), Quelques données sur les sondages de l'INSEE en 1952-53, JSSP, 65-196.

Thionet P. (1954b), L'enquête annuelle par sondage sur les salaires et la main d'oeuvre salariée permanente en agriculture, Suppl. BMS, A vril- juin, p.1.

Thionet P. (1958), La perte d'information par sondage, These de doctorat, París. THIONET P. (1978), "Quelques problèmes concernant les sondages». Gottingen, Vandenhoeck \& Ruprecht, 137 p.

TOUCHELAY B. (1993), «L'INSEE des origines a 1961 : évolution et relation avec la réalité économique, politique et sociale», These París XII.

YATEs F. (1949), Sampling Methods for Censuses and Surveys. Londres, Griffin. Trad. fr. bajo la dirección de G. Darmois, París, Masson, 1950. 


\title{
RESUMEN
}

Después de contemplar las etapas de la historia de los sondeos desde Laplace a Neyman (1934), nos centramos en analizar como Stoetzel introdujo las encuestas representativas y los sondeos (exactamente la selección intencionada y los estudios de opinión) en diferentes institutos de estadística (IFOP, SNS, Carrel Foundation) justo antes y durante la II Guerra Mundial. Pero este escrito está dedicado principalmente al último Pierre Thionet que era responsable junto a Raymond Lévy-Bruhl de la introducción del muestreo aleatorio en el recien creado INSEE. En 1946 publica una revisión crítica de los métodos de muestreo en revistas americanas, mientras Lévy-Bruhl estaba visitando la Oficina del Censo y el departamento de estadísticas de trabajo americanos (Boureau of Labour Statistics). En aquel momento trabajaban en el INSEE en el diseño de encuestas representativas sobre presupuestos familiares (1946-48) y empleo (1950-54), y ambos estuvieron implicados en controvorsias con los estadísticos del INED y el IFOP que defendían la selección intencionada.

\begin{abstract}
At first, we give an historical view of sampling from Laplace to Neyman (1934), after that, we describe how Stoetzel introduced sampling and pooling (more exactly purposive selection and opinion) in several French Institutes of Statistics as the IFOP, SNS and Carrel Fundation, just before and during World War II. But this paper is principally dedicated to the late Pierre Thionet (1916-2002) who was responsible with Raymond Lévy-Bruhl of the introduction of random sampling at the INSEE. He published in 1946 a critical review of sampling methods in American Journals while Lévy-Bruhl was visiting the american Bureau of Census and the Boureau of Labour Statistics. Both of them were working at the INSEE on sample surveys on family budgets (1946-48) and employment (1950-54) and they were involved into some controverses with the statisticians who defended purposive sampling from the INED and the IFOP institutes.
\end{abstract}

